\title{
BIOETHANOL PRODUCTION FROM SUGARCANE BAGASSE PRETREATED BY TRICHODERMA VIRIDE
}

\author{
Muhammad Alfian Mizar ${ }^{1 *}$, Mohamad Amin ${ }^{2}$, Mokhamad Sholihul Hadi ${ }^{1}$, Muhammad Aziz ${ }^{3}$, Sulfahri ${ }^{4}$ \\ ${ }^{1}$ Universitas Negeri Malang, Faculty of Engineering, Malang, Indonesia \\ ${ }^{2}$ Universitas Negeri Malang, Faculty of Mathematics and Natural Sciences, Malang, Indonesia \\ ${ }^{3}$ The University of Tokyo, Institute of Industrial Science, Tokyo, Japan \\ ${ }^{4}$ Hasanuddin University, Faculty of Mathematics and Natural Sciences, South Sulawesi, Indonesia
}

Preservation of fossil fuels are currently depleting with the massive exploitation of fuels. In this condition, breakthroughs are necessary to produce alternative fuels. One of the breakthroughs is bioethanol. It is a renewable energy which is more effective than gasoline inasmuch it can increase combustion efficiency and reduce exhaust emissions. In this work, a bioethanol process was done by using sugarcane bagasse waste material which has a lot of lignin and cellulose content. The content was converted into bioethanol by utilizing a strong base to degrade lignin and $T$. Viride as cellulose-producing and S. cereviseae yeast as a sugar converter to bioethanol. This present research aims to find the best formula of bioethanol production based on sugarcane bagasse with variations in cellulose hydrolysis temperature, shaking speed, and fermentation time by using an integrated shaker machine fuzzy-logic control of temperature and humidity. This research employed a complete randomized design experimental research (CRD) to test temperature, speed, and time modification by using a shaker machine. The independent variables were: (1) temperature, (2) shaking speed, and (3) fermentation time. The dependent variables measured were reducing sugar and bioethanol levels. The results showed that the best formula for producing bioethanol levels was at a treatment temperature of $45^{\circ} \mathrm{C}$ and a speed of $140 \mathrm{rpm}$ with fermentation time of 48 hours which resulted in a bioethanol level of $2.75 \%$.

Key words: bioethanol, sugarcane bagasse, reducing sugar, pretreatment, microbial

\section{INTRODUCTION}

Almost all economic activities require a supply of fuel as energy and most of the fuel used is fossil. If exploited on a large scale, it results in depletion of fossil fuel reserves and rising prices. According to data from the Ministry of Energy and Mineral Resources in 2018, Indonesia only has oil reserves of around 3.3 billion barrels, assuming a day of crude oil production of 800 thousand barrels. As a result, in the next 11-12 years oil reserves in Indonesia will be vanishing.

One attempt to reduce dependence on fossil fuels is to employ renewable energy that can replace fossil fuels such as bioethanol, biosolar, biohydrogen, and others. Bioethanol is a renewable fuel that is quite promising and more effective than gasoline inasmuch it can increase combustion efficiency and reduce exhaust emissions [1]. Bioethanol can be made by using materials containing lignocelluloses which, when reduced, will diminish sugars in the forms of glucose, mannose, xylose, galactose and arabinose, and can be converted to bioethanol $[2,3]$. Production of plant-based bioethanol which can still

be consumed is ineffective and can cause food problems; therefore, we need more realistic bioethanol raw materials such as the rest of the agricultural and plantation production such as rice straw, corncobs, and bagasse which is one of the sufficient available materials nowadays. Indonesia has a very high potential since it has
450000 ha of sugarcane planted with sugar production of 2.53 million tons in 2015 [4]. Meanwhile, sugarcane mill waste reaches $14-40 \%$ by weight sugarcane as a sugar ingredient. This volume is potential enough to be used as a bioethanol material [5].

Sugarcane bagasse has around $50 \%$ cellulose. This content is higher than other ingredients such as corncobs which only have $40 \%$ cellulose content [6]. This means that the reducing sugar content obtained from saccharification process can be fermented to produce higher bioethanol, assuming 80 liters of bioethanol is produced from 1 ton of sugarcane. If sugarcane productivity is 80 tons per hectare, each hectare of sugarcane land produces 6400 liters of bioethanol. Bioethanol from sugarcane can substitute $20 \%$ of gasoline needs $[5,7]$. Increasing levels of bioethanol is imperative in order to obtain increased efficiency of bioethanol yield. Some techniques used to obtain efficient ethanol yield can be completed with preliminary stages of physical, physical-chemical, and biological processes. Physical engineering is usually carried out by mechanical breakdown in order to obtain small materials so as to facilitate the process of breaking down cellulose in materials. Meanwhile, chemical techniques are usually with acid hydrolysis, alkaline hydrolysis, and many more. In term of biological treatment, many microorganisms appear such as molds from species such as Polyporusbrumalis, and Lentinusedodes [8]. 
Research conducted by [9] investigated the xylanases produced by Trichoderma viride and Trichoderma piluliferum. Both the enzyme extracts produced were effective at increasing digestibility of sugarcane silage and corn silage. The enzymatic extracts proved promising for xylooligo-saccharides production and showed low cellulase activity, indicating potential for application in biobleaching processes of cellulose. Furthermore, research conducted by [10] found that solid culture experiments demonstrated Trichoderma viride and $A$. terreus as the most compatible strains with Leptosphaerulina $\mathrm{sp}$. The use of fungal co-culture as inducers obtained superior results than previously used chemical inducers. These results revealed the potential of co-cultivation as an alternative for enzymatic induction and pollutants bioremediation. But, in their study $[9,10]$ not varying the treatment on shaker machines. According to [11] the use of shakers serves as a stirring so that the reagent substances can collide well. It is also contended that the higher the hydrolysis temperature, the better the saccharification process is [12].

Given the aforementioned complexities above, this present study seeks to find the best formula of bioethanol production based on sugarcane bagasse with variations in cellulose hydrolysis temperature, shaking speed, and fermentation time by using an integrated shaker machine that controls fuzzy-logic temperature and humidity.

\section{MATERIALS AND METHODS}

\section{Materials}

The object used in this research was bagasse in the form of waste in the process of making sugar from Mitra Agung Sugar Factory in Malang, East Java, Indonesia. Waste material of bagasse was dried by using an oven at $80{ }^{\circ} \mathrm{C}$ for $48 \mathrm{~h}$. The dried material was then blended until it was crushed and sieved with a size of 40 mesh.

Trichoderma viride and Saccharomyces cereviseae cultures were bred in the Microbiology Laboratory of Universitas Negeri Malang, East Java, Indonesia. The culture preparations in this study included Trichoderma viride and Saccharomyces cereviseae on new medium so that they could grow optimally.

\section{Culture preparation of microbial}

Trichoderma viride was cultured on PDA media and incubated at $28^{\circ} \mathrm{C}$ for 9 days. Furthermore, a starter 1 was made by adding 3 ose Trichoderma viride/ Saccharomyces cereviseae into $15 \mathrm{ml}$ of the dissolved material. Starter 1 was placed in a shaker with a speed of $120 \mathrm{rpm}$ for $24 \mathrm{~h}$. Furthermore, a starter 2 was done by adding 3 $\mathrm{ml}$ of starter 1 to $27 \mathrm{ml}$ of the material solution. Starter 2 was placed on a shaker with a speed of $120 \mathrm{rpm}$ for $24 \mathrm{~h}$. Furthermore, a starter 3 was done by adding starter 2 as much as $10 \%$ of the material to be used in the treatment then it was placed in a shaker machine with a speed of $120 \mathrm{rpm}$ in $96 \mathrm{~h}$ for Trichoderma viride and $120 \mathrm{rpm}$ in $48 \mathrm{~h}$ for Saccharomyces cereviseae.

\section{Chemical pretreatment}

Chemical pretreatment was done to remove the lignin content in the ingredients, and at this stage, $50 \mathrm{~g}$ of bagasse powder was soaked in 1 liter of natrium chloride for $5 \mathrm{~h}$. Besides, the powder was washed until the smell diminished. Furthermore, sterilization was performed by using an autoclave at $121^{\circ} \mathrm{C}$ for $15 \mathrm{~min}$.

\section{Bioethanol production}

Bioethanol production in this research was carried out by saccharification and fermentation processes. Trichoderma viride and yeast cultures were done simultaneously through Saccarification and Fermentation (SSF) processes. The SSF method was done by giving Trichoderma viride and Saccharomyces cereviseae together. The shaking treatment was carried out by using an integrated Fuzzy Logic temperature and humidity shaker machine according to the study design. The culture technique was carried out by adding $5 \mathrm{ml}$ each of the 3 Trichoderma viride and Saccharomyces cereviseae starter to $30 \mathrm{ml}$ of treated sugarcane bagasse material and $10 \mathrm{ml}$ of Andreoti media in a modified fermenter bottle. The $\mathrm{pH}$ is adjusted to 4 by adding $3 \mathrm{M}$ Hydrochloric acid Hydrolysis and fermentation were carried out at temperatures according to the study design of 25,35 , and $45^{\circ} \mathrm{C}$, with variations in speeds of 60,100 and $140 \mathrm{rpm}$ and lengths of 24,48 , and $72 \mathrm{~h}$.

\section{Analytical}

Measurement of the sugars levels was carried out by using Nelason method. Measurement of the ethanol levels was carried out by using a pocket refractometer.

\section{Research Design}

This study employed an experimental design to test the modification of temperature, speed and time of fermentation by using a completely randomized design (CRD) with twenty-seven treatments and two replications. The independent variables were: (1) temperature, (2) shaking speed, and (3) fermentation and the dependent variable measured was the level of reducing sugars and the level of bioethanol produced.

\section{RESULTS AND DISCUSSION}

\section{Reducing sugar production}

Reducing sugar was converted into bioethanol by using Saccharomyces cerevisiae. The more the reducing sugarproduced, the higher the level of bioethanol is [13]. To construe the trend of the enzymatic activity of Trichoderma viride in producing reducing sugars, saccharification was carried out at $25^{\circ} \mathrm{C}$ with a speed of $100 \mathrm{rpm}$ based on saccharification timing process. In terms of the acquisition of reducing sugar levels at a temperature of $25^{\circ} \mathrm{C}$ with a speed of $100 \mathrm{rpm}$ for 24 hours, it generates the lowest reducing sugar levels of $4162.83 \mu \mathrm{g}$, while 


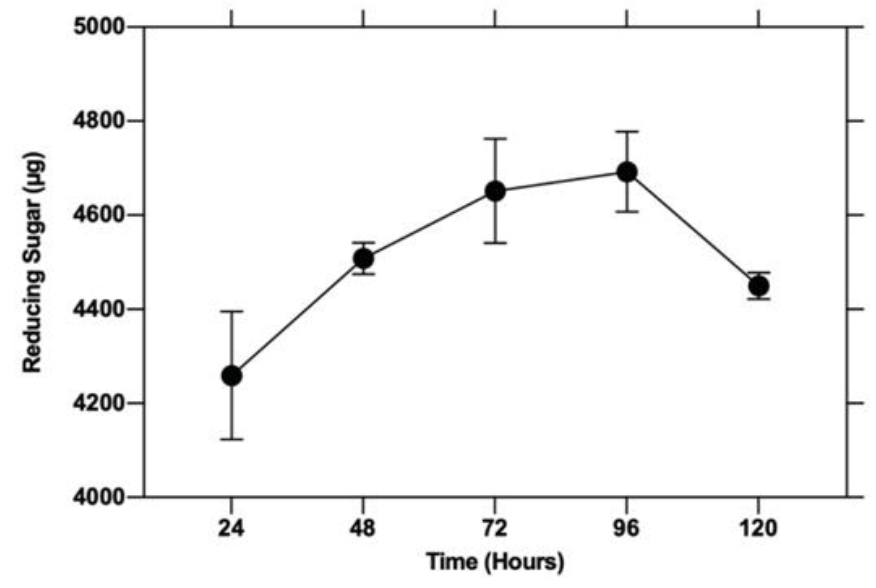

Figure 1: Reducing Sugar $(\mu \mathrm{g})$ vs time of saccharification time

the highest reducing sugar levels of $4752.43 \mu \mathrm{g}$ were obtained at $96 \mathrm{~h}$. It then decreased at the treatment time of $120 \mathrm{~h}$ to $4429.96 \mu \mathrm{g}$. Data from the measurement of Reducing sugar content on bagasse using the Nelson method is presented in Figure 1.

Reducing sugar was produced through saccharification and simplified cellulose processes which was converted into simple sugars in the form of glucose [14]. Reducing sugar can be formed due to the enzymatic reaction produced by Trichoderma viride which produces the cellulase enzyme. Cellulase enzymes are a group of enzymes consisting of several enzymes working synergistically to break down cellulose. The enzyme group is the endoglucanase enzyme that randomly changes cellulose and forms a free end chain. The exoglunase enzyme degrades molecules that have been broken down by endoglucasease and removes the cellubiosa unit from the free end and the last enzyme, $\beta$-glucosidase, converts the cellubiose into a simpler sugar glucose [3,15].

This research was carried out through saccharification on bagasse delignified by using Trichoderma viride which was shaken by using a shaker machine with a speed of $100 \mathrm{rpm}$ at a temperature of $25^{\circ} \mathrm{C}$ within $24 \mathrm{~h}$ long. It was obtained from the reducing sugar amounted to 4354.94 $\mu \mathrm{g}$. During $48 \mathrm{~h}, 4531.35 \mu \mathrm{g}$ was obtained. Meanwhile $4729.76 \mu \mathrm{g}$ was gained within $72 \mathrm{~h}$. The increase still continued at $96 \mathrm{~h}$ with $4752.43 \mu \mathrm{g}$. These data indicate that there was an increase in reducing sugar levels at each $24 \mathrm{~h}$ treatment period. The increase was due to an increase in cellulase enzyme activity; but after the 120 hour treatment, the reducing sugar showed a decrease. This occurred inasmuch the activity of the cellulase enzyme decreased with increasing hours. It is showed that the optimum time of the saccharification process with the help of molds was $48 \mathrm{~h}$ after which it would decrease its reducing sugar levels [10].

Other factors influencing the results of the reducing sugars are the amount of mold inoculants and the temperature of the saccharification process. Factors of mold inoculants will be directly related to the concentration of enzymes produced by these molds since the more molds used, the more enzymes produced. Thus, the saccharification process will be faster. The reaction rate can be increased according to the increase in the concentration of the enzyme used [14]. The temperature factor is also one of the factors determining the outcome of saccharification. It is contended that the optimal reaction rate was around $45-50{ }^{\circ} \mathrm{C}$. On the other hand, excessive temperature rise will damage the enzymes used for the saccharification process inasmuch enzymes are composed of proteins that will be denatured at high temperatures [16].

\section{Bioethanol production}

Data from the measurement of bioethanol by using the simultaneous saccharification fermentation (SSF) method at temperature, speed and time of treatment are presented in Figure 2.

The results of this study indicate that the best bioethanol production formula made from bagasse has a bioethanol content of $2.75 \%$ at $45{ }^{\circ} \mathrm{C}, 140 \mathrm{rpm}$ shaking speed, and $48 \mathrm{~h}$ fermentation time fermented by using an integrated shaker machine fuzzy-logic control temperature and humidity. Furthermore, lowest bioethanol levels are $0 \%$ at a temperature of $25^{\circ} \mathrm{C}$, a speed of $60 \mathrm{rpm}$, and $24 \mathrm{~h}$ fermentation time.

The fermentation process is a process of changing simple sugars produced from the saccharification process into bioethanol. The processes used were simultaneous saccharification and fermentation (SSF). The SSF method is considered better than other methods inasmuch it increases the rate of the fermentation process since there is integration between the processes of saccharification and fermentation simultaneously and because the sugar formed from the direct saccharification process can be used as a raw material in the fermentation process. Thus, the emergence of acetic acid inhibitors can be avoided [17].

This study also indicates that the highest bioethanol content of $2.75 \%$ is obtained from the treatment at a temperature of $45^{\circ} \mathrm{C}$ with a shaking speed of $140 \mathrm{rpm}$ shaker

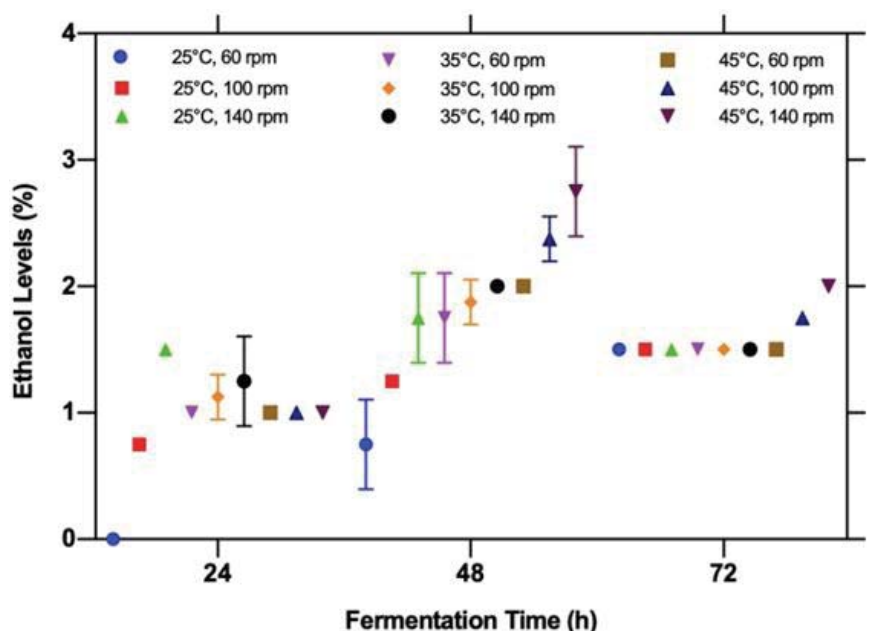

Figure 2: Effect of temperature, shaking speed an fermentation time on ethanol levels 
engine and $48 \mathrm{~h}$ of fermentation time. This is consistent with the theory that the higher the temperature, the faster the bioethanol produced. Likewise, the cellulose hydrolysis process requires a high temperature which is around $45-50{ }^{\circ} \mathrm{C}$ [18]. Besides, shaking can also help increase reaction rate of the fermentation process. This happens because the faster the stirring in the process of making bioethanol, the higher the value of bioethanol yields. Stirring will result in contact between the reactant and the substrate so that a reaction occurs more quickly. Thus, Saccharomyces cerevisiae produces more invertase enzymes that play a role in the fermentation process so that it can convert glucose more quickly to produce bioethanol.

This study, additionally, portrayed that the highest levels of bioethanol were obtained at the time of fermentation for $48 \mathrm{~h}$ and would decrease at $72 \mathrm{~h}$. This happens because the best time for fermentation is $50 \mathrm{~h}$ [17]. The longer fermentation will reduce the rate of bioethanol fermentation since the nutrients present in the media decreases so that Saccharomyces cerevisiae will not be able to convert glucose into bioethanol. In addition, if fermentation is carried out longer, the alcohol content will actually decrease as alcohol will be converted into other compounds such as acetic acid and esters [19].

\section{CONCLUSION}

Based on this study, the best formula to produce the highest levels of bioethanol of $2.75 \%$ was obtained at $45^{\circ} \mathrm{C}$ with $48 \mathrm{~h}$ fementation time by using an integrated shaker engine controlling temperature and humidity at a speed of $140 \mathrm{rpm}$. This study then encourages further research on the other microbial-aided bioethanol, the method of saccharification and fermentation in stages, and bioethanol made from other types of raw materials that can reduce environmental waste.

\section{ACKNOWLEDGMENTS}

The authors would like to thank greatfully to Universitas Negeri Malang for supporting the research funding. We are also thank you to head and the researcher and member molecular biology working group for the technical support.

\section{REFERENCES}

1. Sulfahri, Ni'matuzahroh, and Manuhara S. W. (2016) Studies on The Hungate technique for ethanol fermentation of algae Spirogyra hyalina using Saccharomyces cerevisiae, Biofuels.

2. Sulfahri, Amin M., Sumitro S. B., and Saptasari M., (2016) Bioethanol production from algae Spirogyra hyalina using Zymomonasmobilis,Biofuels, 7(6).

3. Chen W. et al. (2017) Journal of the Taiwan Institute of Chemical Engineers Producing bioethanol from pretreated-wood dust by simultaneous saccharification and co-fermentation process. 79:43-48
4. Pradana Y. S., Hartono M., Prasakti L., and Budiman A. (2019) Effect of calcium and magnesium catalyst on pyrolysis kinetic of Indonesian sugarcane bagasse for biofuel production. Energy Procedia, 158:431-439.

5. de Araujo Guilherme A., Dantas P. V. F., de AC. E. Padilha, dos Santos E. S., and de Macedo G. R. (2019) Ethanol production from sugarcane bagasse: Use of different fermentation strategies to enhance an environmental-friendly process, J. Environ. Manage, 234:44-51.

6. Chen W., YeS., and Sheen H. (2012) Hydrolysis characteristics of sugarcane bagasse pretreated by dilute acid solution in a microwave irradiation environment. Appl. Energy, 93:237-244.

7. Delabona S., Sanchez C., Ribeiro M., Freitas S., and Geraldo J. (2012) Bioresource Technology Use of a new Trichoderma harzianum strain isolated from the Amazon rainforest with pretreated sugar cane bagasse for on-site cellulase production. Bioresour. Technol, 107:517-521.

8. Lee S., Kim M., Kim S., Hong C., Ryu S., and Choi I. (2016) Transcriptomic analysis of the white rot fungus Polyporusbrumalis provides insight into sesquiterpene biosynthesis, 182:141-149.

9. Carolina A. et al. (2019) Biocatalysis and Agricultural Biotechnology Catalytic properties of xylanases produced by Trichoderma piluliferum and Trichoderma viride and their application as additives in bovine feeding. 19.

10. Copete-pertuzL. S., Alandete-novoa F., Placido J., Correa-londono G. A., and Mora-martinez A. L., (2019) Science of the Total Environment Enhancement of ligninolytic enzymes production and decolourising activity in Leptosphaerulinasp . by co cultivation with Trichoderma viride and Aspergillus terreus. Sci. Total Environ., 646:1536-1545.

11. Haghighi S., Hossein A., and Tabatabaei M., (2013) Lignocellulosic biomass to bioethanol , a comprehensive review with a focus on pretreatment, 27:77-93.

12. Pongcharoen P., Chawneua J., and Tawong W., (2018) High temperature alcoholic fermentation by new thermotolerant yeast strains Pichia kudriavzevii isolated from sugarcane field soil. Agric. Nat. Resour., 52(6):511-518.

13. Tian S., Zhao R., and Chen Z. (2017) Review of the pretreatment and bioconversion of lignocellulosic biomass from wheat straw materials. Renew. Sustain. Energy Rev., 91:pp. 483-489.

14. Waheed A. et al. (2017) Insight into progress in pre-treatment of lignocellulosic biomass. Energy, 122: 724-745.

15. Chuck, C. J., Parker H. J., Jenkins R. W., and Donnelly J. (2013) Bioresource Technology Renewable biofuel additives from the ozonolysis of lignin.Bioresour. Technol., 143:549-554. 
16. Jahnavi G., Prashanthi G. S., Sravanthi K., and Rao L. V. Status of availability of lignocellulosic feed stocks in India : Biotechnological strategies involved in the production of Bioethanol," Renew. Sustain. Energy Rev., 73:798-820.

17. Zhuang X. et al. (2016) Bioresource Technology Liquid hot water pretreatment of lignocellulosic biomass for bioethanol production accompanying with high valuable products. Bioresour. Technol., 199:68-75.
18. Byadgi S. A. and Kalburgi P. B. (2016) Production of Bioethanol from Waste Newspaper. Procedia Environ. Sci., 35:555-562.

19. Luong C., Duy L., and Kameil. (2018) International Biodeterioration \& Biodegradation The improvement of sodium hydroxide pretreatment in bioethanol production from Japanese bamboo Phyllostachys edulis using the white rot fungus Phlebiasp. MG-60.Int. Biodeterior. Biodegrad., 133:86-92. 